Taksonomia 29

ISSN 1899-3192

Klasyfikacja i analiza danych - teoria i zastosowania

e-ISSN 2392-0041

\title{
Beata Bieszk-Stolorz
}

Uniwersytet Szczeciński

e-mail: beatus@wneiz.pl

\section{FUNKCJA SKUMULOWANEJ CZECSTOŚCI \\ I MODELE HAZARDU W OCENIE KONKURUJĄCYCH FORM WYJŚCIA Z BEZROBOCIA}

\section{CUMULATIVE INCIDENCE FUNCTION AND HAZARDS MODELS IN THE ASSESSMENT OF ROUTES FOR UNEMPLOYMENT EXIT}

DOI: $10.15611 /$ pn.2017.469.02

JEL Classification: C41, J64

Streszczenie: W analizie czasu trwania bezrobocia rejestrowanego występują dane cenzurowane dwojakiego rodzaju. Jeżeli zdarzeniem kończącym obserwację jest podjęcie pracy, to obserwacjami cenzurowanymi są przypadki wyrejestrowania z pozostałych przyczyn (np. przejście na rentę lub emeryturę, wyjazd za granicę, niezgłoszenie się w urzędzie) lub obserwacje, które nie zakończyły się zdarzeniem przed końcem okresu badania. Pojęcie podjęcie pracy obejmuje różne formy wyjścia z bezrobocia: podjęcie zatrudnienia lub działalności gospodarczej, skorzystanie z subsydiowanych form zatrudnienia: prac interwencyjnych lub robót publicznych. Wszystkie te formy stanowią różne rodzaje zdarzeń konkurujących. Celem artykułu jest wykorzystanie funkcji skumulowanej częstości do oceny prawdopodobieństwa wyjścia z bezrobocia oraz modeli hazardu do oceny intensywności tego wyjścia dla różnych rodzajów ryzyk konkurujących. Zastosowane metody pozwoliły na ocenę wpływu innych niż praca przyczyn wyrejestrowania z urzędu pracy.

Słowa kluczowe: funkcja skumulowanej częstości $C I F$, model hazardu, ryzyka konkurujące, bezrobocie.

Summary: The survival analysis of registered unemployment uses censored data of two kinds. If the final event of the observation is a jobseeker's employment, then we can accept for censored observations the cases of leaving the register for other reasons (retirement due to old-age pension or permanent disability, a failure to report to the labour office) or the observations which had not finished with an event before the end of the study. Moreover, the very act of taking up income-generating work can take various forms: taking up a job, setting up a business or taking advantage of subsidised job programmes offered by local governments, such as intervention or public works. All of these forms are considered to be some form of competing risk. The purpose of the article is to use the cumulative incidence function (CIF) to evaluate the probability to leave unemployment and to use the hazards models to assess the intensity of leaving unemployment in reference to various types of the competing risk.

Keywords: cumulative incidence function (CIF), hazard model, competing risks, unemployment. 


\section{Wstęp}

Analiza trwania, nazywana często analizą przeżycia, obejmuje zbiór metod badających procesy, w których interesujący jest czas $T$, jaki upłynie do wystąpienia pewnego zdarzenia. Obserwacji podlegają wszystkie jednostki należące do pewnej kohorty (pacjenci, urządzenia, bezrobotni, firmy). Obserwuje się czas trwania zjawiska (procesu), jaki upływa od zdarzenia początkowego (początek leczenia, uruchomienie urządzenia, utrata pracy, założenie firmy) do zajścia zdarzenia końcowego (śmierć pacjenta, awaria urządzenia, wyjście z bezrobocia, likwidacja firmy). Ponieważ okres obserwacji jest ograniczony, zdarza się, że jednostki należące do badanej kohorty mogą nie doznać zdarzenia końcowego przed jego końcem. Takie obserwacje uznaje się za cenzurowane prawostronnie. W badaniach za obserwacje takie uznaje się również sytuacje, w których badana jednostka znika z pola widzenia lub występuje zdarzenie kończące obserwację, które wyklucza zajście zdarzenia właściwego [Pepe 1991], czyli zdarzenie konkurujące. Gooley $\mathrm{i}$ in. [1999] definiuje ryzyko konkurujące jako zdarzenie, którego wystąpienie wyklucza lub fundamentalnie zmienia prawdopodobieństwo wystąpienia innego zdarzenia. Należy przy tym założyć, że zdarzenia występują niezależnie od siebie [Crowder 1994, 1996, 1997]. Badana jednostka jest narażona na różne rodzaje ryzyka w tym samym czasie, ale przypuszcza się, że ewentualne zdarzenie wynika z tylko jednego z tych czynników, które nazywa się „przyczyną niepowodzenia” [Aly i in. 1994]. Jeżeli badamy śmiertelność pacjentów w wyniku wykrytej choroby, obserwacji może podlegać czas upływający od momentu podjęcia leczenia do momentu śmierci. Śmierć może nastąpić z powodu nawrotu choroby lub w czasie remisji (spowodowanej skutkami leczenia). W zastosowaniach inżynierskich ryzyko konkurujące związane jest $\mathrm{z}$ wpływem elementów składowych na cały system. Tutaj awaria któregokolwiek ze składników powoduje awarię systemu. Obserwuje się czas, w którym system zawodzi, i który składnik spowodował awarię. W literaturze obok zdarzeń konkurujących bezwarunkowych (unconditional competing risks), rozważa się również warunkowe modele ryzyk konkurujących (conditional competing risks models). W przypadku pierwszego rodzaju zdarzeń zakłada się ich niezależność. W przypadku tych drugich prawdopodobieństwa przejścia między stanami zależą nie tylko od zmiennych objaśniających, ale również od czasu i typu pobytu we wcześniejszym stanie [Landmesser 2008b].

Celem artykułu jest wykorzystanie wybranych metod oceny ryzyk konkurujących bezwarunkowych: funkcji skumulowanej częstości CIF (Cumulative Incidence Function) do oceny prawdopodobieństwa wyjścia z bezrobocia oraz modeli hazardu do oceny intensywności wychodzenia $z$ bezrobocia dla różnych rodzajów ryzyk konkurujących. W badaniu wykorzystano dane indywidualne osób zarejestrowanych w Powiatowym Urzędzie Pracy (PUP) w Szczecinie. 


\section{Metodyka badania}

W badaniu wykorzystano wybrane metody analizy trwania. Obserwacji podlega czas trwania jednostki w danym stanie, który jest zmienną losową $T$. Podstawą tego typu analizy jest funkcja trwania (funkcja przeżycia) zdefiniowana następująco:

$$
S(t)=P(t>T)=1-F(t),
$$

gdzie: $T$ jest czasem trwania zjawiska, a $F(T)$ - dystrybuantą rozkładu zmiennej losowej $T$.

Drugą funkcją stosowaną w analizie trwania jest funkcja hazardu. Opisuje ona intensywność zajścia zdarzenia w momencie $t$ pod warunkiem przetrwania do czasu $t \mathrm{i}$ jest zdefiniowana następująco [Kleinbaum, Klein 2005]:

$$
h(t)=\lim _{\Delta t \rightarrow 0} \frac{P(t \leq T<t+\Delta t \mid T \geq t)}{\Delta t} .
$$

Natomiast funkcja skumulowanego hazardu jest sumą hazardu do czasu $t$ i dla czasu dyskretnego określona jest wzorem:

$$
H(t)=\sum_{j: t_{j} \leq t} h\left(t_{j}\right) .
$$

W przypadku występowania różnych zdarzeń konkurujących stosuje się funkcję skumulowanej częstości występowania (Cumulative Incidence Function) oznaczoną jako $C I F_{k}(t)$. Jest to prawdopodobieństwo zajścia zdarzenia z powodu $k$ przed czasem $t$. Funkcja ta jest zdefiniowana następująco [Klein, Moeschberger 2003, s. 52]:

$$
C I F_{k}(t)=P(t \leq T, \delta=k)=\int_{0}^{t} S(u) h_{k}(u) d u=\int_{0}^{t} S(u) d H_{k},
$$

gdzie: $H_{k}(t)$ dla $k=1,2,3, \ldots, K$ jest funkcją hazardu skumulowanego, $S(t)-$ funkcją przeżycia, $\delta=0$ dla obserwacji cenzurowanych oraz $\delta=1, \ldots, K$ dla obserwacji kończących się zdarzeniem typu $k$ (jednym z $K$ konkurujących).

Estymatorem funkcji skumulowanego hazardu $H_{k}(t)$ dla przyczyny $k$ jest estymator Nelsona-Aalena:

$$
\hat{H}_{k}(t)=\sum_{j: t_{j} \leq t} \frac{d_{k j}}{n_{j}},
$$

gdzie: $t_{j}$ są momentami zachodzenia zdarzeń, $d_{k j}$ jest liczbą zdarzeń z powodu zaistnienia przyczyny $k$ w momencie $t_{j}, n_{j}$ jest liczbą osób narażonych na ryzyko w czasie $t_{j}$ 
Często stosowanym estymatorem funkcji przeżycia $S(t)$ jest estymator Kaplana-Meiera:

$$
\hat{S}(t)=\prod_{j: t_{j} \leq t}\left(1-\frac{d_{j}}{n_{j}}\right),
$$

gdzie: $d_{j}$ oznacza liczbę zdarzeń w momencie $t_{j}$, a $n_{j}$ jest liczbą osób narażonych na ryzyko w czasie $t_{j}$.

Korzystając ze wzorów (5) i (6), funkcję skumulowanej częstości występowania z powodu zaistnienia przyczyny $k$ można oszacować jako [Marubini, Valsecchi 1995]:

$$
C \hat{I} F_{k}(t)=\sum_{j: t_{j} \leq t} \hat{S}\left(t_{j-1}\right) \frac{d_{k j}}{n_{j}} .
$$

$C I F_{k}$ jest skumulowanym prawdopodobieństwem wystąpienia zdarzenia typu $k$ przed lub w czasie $t$ [Bryant, Dignam 2004]. Pozwala ono określić wzorce zajścia zdarzenia z powodu $k$ oraz ocenić, w jakim stopniu każdy powód przyczynia się do całkowitej porażki ${ }^{1}$.

Ponieważ $\sum_{k=1}^{K} d_{k j}=d_{j}$, to prawdziwa jest zależność:

$$
\sum_{k=1}^{K} C \hat{I} F_{k}(t)=1-\hat{S}(t)
$$

Jeżeli nie ma zdarzeń konkurujących, to zachodzi równość:

$$
C \hat{I F}(t)=1-\hat{S}(t) \text {. }
$$

W przypadku, gdy występują zdarzenia konkurujące stosuje się również rozwiązanie polegające na uznaniu pozostałych zdarzeń kończących proces obserwacji za obserwacje cenzurowane. Taki sposób rozumowania prowadzi do przeszacowania wartości funkcji CIF [Sherif Bintu 2004].

W przypadku różnych rodzajów ryzyk konkurujących $(k \geq 1)$ funkcje hazardu opisuje wzór [Klein, Moeschberger 2003, s. 50]:

$$
h_{k}(t)=\lim _{\Delta t \rightarrow 0} \frac{P(t \leq T<t+\Delta t, \delta=k \mid T \geq t)}{\Delta t} \text { dla } k=1,2,3, \ldots, K .
$$

${ }^{1}$ Innym sposobem oceny ryzyka konkurującego jest zastosowanie wielomianowego modelu logitowego (jako model hazardu z czasem dyskretnym) i wyznaczenie szansy względnej zajścia zdarzeń konkurujących [Landmesser 2008a; Bieszk-Stolorz, Markowicz 2012]. 
Estymatorem funkcji hazardu $h_{k}(t)$ dla przyczyny $k \mathrm{w}$ momencie $t_{j}$ jest:

$$
\hat{h}_{k}\left(t_{j}\right)=\frac{d_{k j}}{n_{j}}
$$

gdzie $d_{k j}$ i $n_{j}$ mają takie same znaczenie jak we wzorze (5). W przypadku, gdy $k=1$ (brak zdarzeń konkurujących), estymator funkcji hazardu przyjmuje postać:

$$
\hat{h}\left(t_{j}\right)=\frac{d_{j}}{n_{j}},
$$

gdzie $d_{j}$ i $n_{j}$ mają takie same znaczenie jak we wzorze (6). Modele dane wzorami (11) i (12) nazywa się również modelami hazardu empirycznego.

\section{Dane wykorzystane w badaniu i rodzaje grup zdarzeń kończących proces obserwacji}

W badaniu wykorzystano anonimowe dane indywidualne 22078 osób bezrobotnych zarejestrowanych w 2013 roku w Powiatowym Urzędzie Pracy w Szczecinie i obserwowanych do końca 2014 roku. Wyznaczono czas od momentu zarejestrowania do momentu wyrejestrowania $\mathrm{z}$ urzędu z określonego powodu. Liczne przyczyny wyrejestrowania pogrupowano (tab. 1). Ponieważ tylko kilka z nich związanych jest z podjęciem pracy, pierwotnie w badaniu przyjęto bardziej szczegółowy podział na siedem podgrup przyczyn wyrejestrowania: praca, praca (urząd), działalność gospodarcza, odmowa, renta/emerytura/zasiłek, wyjazd za granicę i pozostałe. Następnie, opierając się na pierwszych analizach, przyczyny podzielono na trzy grupy: praca w ogólnym sensie, odmowa i pozostałe.

Tabela 1. Grupy przyczyn wyrejestrowania z urzędu pracy

\begin{tabular}{|l|l|l|}
\hline \multicolumn{1}{|c|}{$\begin{array}{c}\text { Nazwa } \\
\text { grupy }\end{array}$} & $\begin{array}{c}\text { Nazwa } \\
\text { podgrupy }\end{array}$ & \multicolumn{1}{c|}{ Przyczyna wyrejestrowania } \\
\hline 1 & \multicolumn{1}{|c|}{2} & \multicolumn{1}{c|}{3} \\
\hline $\begin{array}{l}\text { Praca } \\
\text { w ogólnym } \\
\text { sensie }\end{array}$ & $\begin{array}{l}\text { praca } \\
\text { praca } \\
\text { (urząd) }\end{array}$ & $\begin{array}{l}\text { podjęcie pracy lub innego zatrudnienia } \\
\text { podjęcie robót publicznych, prac interwencyjnych, praca w ramach } \\
\text { utworzonego dodatkowego miejsca pracy z tytułu udzielonej pożyczki } \\
\text { lub dofinansowania wynagrodzenia za zatrudnienie bezrobotnego 50+ }\end{array}$ \\
\cline { 2 - 3 } & $\begin{array}{l}\text { działalność } \\
\text { gospodarcza }\end{array}$ & $\begin{array}{l}\text { podjęcie pozarolniczej działalności gospodarczej, przyznanie } \\
\text { jednorazowo środków na podjęcie działalności gospodarczej, } \\
\text { rozpoczęcie działalności gospodarczej ze środków PFRON }\end{array}$ \\
\hline Odmowa & odmowa & $\begin{array}{l}\text { odmówienie przyjęcia propozycji zatrudnienia lub innej pracy } \\
\text { zarobkowej, wykonywania prac interwencyjnych, robót publicznych, } \\
\text { udziału w szkoleniu, stażu, przygotowaniu zawodowym w miejscu }\end{array}$ \\
\hline
\end{tabular}


Tabela 2, cd.

\begin{tabular}{|l|l|l|}
\hline 1 & \multicolumn{1}{|c|}{2} & \multicolumn{1}{|c|}{3} \\
\hline \multirow{3}{*}{ Pozostałe } & $\begin{array}{l}\text { pracy; niestawienie się w PUP w wyznaczonym terminie, } \\
\text { nieprzedstawienie zaświadczenia o niezdolności do pracy wskutek } \\
\text { choroby, odmówienie lub przerwanie udziału w działaniach w ramach } \\
\text { Programu Aktywizacja i Integracja, brak gotowości do podjęcia pracy } \\
\text { przez okres co najmniej 10 dni, wniosek bezrobotnego o wykreślenie } \\
\text { zasiłek, } \\
\text { emerytura }\end{array}$ & $\begin{array}{l}\text { nabycie prawa do emerytury, świadczenia rehabilitacyjnego, renty, } \\
\text { pobieranie zasiłku stałego, podleganie ubezpieczeniu emerytalno- } \\
\text {-rentowemu z tytułu stałej pracy jako domownik w gospodarstwie } \\
\text { rolnym, pobieranie świadczenia pielęgnacyjnego, dodatku do zasiłku } \\
\text { rodzinnego z tytułu samotnego wychowywania dziecka, pobieranie } \\
\text { zasiłku dla opiekuna, przyznanie prawa do pobierania świadczenia/ } \\
\text { zasiłku przedemerytalnego }\end{array}$ \\
\cline { 2 - 4 } & $\begin{array}{l}\text { wyjazd za granicę na okres co najmniej 30 dni - brak gotowości } \\
\text { za granicę }\end{array}$ & $\begin{array}{l}\text { wozostałe } \\
\text { pomiana miejsca zameldowania lub pobytu poza obszar działania PUP, } \\
\text { niezdolność do pracy wskutek choroby lub przebywania w zamkniętym } \\
\text { ośrodku odwykowym, rozpoczęcie szkolenia organizowanego przez } \\
\text { inny podmiot niż PUP, zgon, powołanie do zasadniczej służby } \\
\text { wojskowej, podjęcie nauki w szkole w systemie dziennym }\end{array}$ \\
\hline
\end{tabular}

Źródło: opracowanie własne.

Tabela 2. Rodzaje grup zdarzeń kończących proces obserwacji i odpowiadające im obserwacje cenzurowane

\begin{tabular}{|c|c|c|c|}
\hline \multicolumn{2}{|c|}{$\begin{array}{l}\text { Zdarzenie kończące } \\
\text { proces obserwacji }\end{array}$} & \multicolumn{2}{|l|}{ Obserwacja cenzurowana } \\
\hline \multicolumn{2}{|l|}{1} & \multicolumn{2}{|l|}{2} \\
\hline Powód wyrejestrowania & Liczba & Powód cenzurowania & Liczba \\
\hline \multicolumn{4}{|c|}{ I rodzaj } \\
\hline Dowolny powód & 20222 & Zdarzenie nie nastąpiło do końca 2014 roku & 1856 \\
\hline \multicolumn{4}{|c|}{ II rodzaj } \\
\hline Praca & 7807 & $\begin{array}{l}\text { Zdarzenie nie nastąpiło do końca } 2014 \text { roku lub } \\
\text { inny niż podjęcie pracy powód wyrejestrowania }\end{array}$ & 14271 \\
\hline \multicolumn{4}{|c|}{ III rodzaj } \\
\hline Praca & 7807 & \multirow{7}{*}{ Zdarzenie nie nastąpiło do końca 2014 roku } & \multirow{7}{*}{1856} \\
\hline Praca (urząd) & 929 & & \\
\hline Działalność gospodarcza & 897 & & \\
\hline Odmowa & 8965 & & \\
\hline Renta, zasiłek, emerytura & 685 & & \\
\hline Wyjazd za granicę & 445 & & \\
\hline Pozostałe & 494 & & \\
\hline
\end{tabular}




\begin{tabular}{|l|r|c|c|}
\hline \multicolumn{2}{|c|}{1} & \multicolumn{2}{|c|}{ IV rodzaj } \\
\cline { 1 - 2 } Praca w ogólnym sensie & 9633 & \multirow{2}{*}{ Zdarzenie nie nastąpiło do końca 2014 roku } & 1856 \\
\cline { 1 - 2 } Odmowa & 8965 & \\
\hline Pozostałe & 1624 & & \\
\hline
\end{tabular}

Źródło: opracowanie własne.

Zastosowanie w badaniu modeli ryzyk konkurujących wiąże się z różnym zdefiniowaniem obserwacji cenzurowanych. Mogą to być bowiem obserwacje, które nie zakończyły się jakimkolwiek zdarzeniem przed upływem okresu obserwacji (w przeprowadzonym badaniu jest to koniec 2014 roku), lub obserwacje, które zakończyły się zdarzeniem różnym od analizowanego. W przeprowadzonym badaniu analizowano cztery rodzaje grup zdarzeń kończących proces obserwacji. Wynikają one z przyjętego wcześniej podziału przyczyn wyrejestrowania. Odpowiadały im różne powody cenzurowania prawostronnego (tab. 2).

\section{Analiza prawdopodobieństwa i intensywności wychodzenia $\mathrm{z}$ bezrobocia}

W pierwszym etapie badania wyznaczono funkcję skumulowanej częstości dla czterech rodzajów grup zdarzeń kończących proces obserwacji. Na rys. 1a i 1b przedstawiono wartości estymatorów Kaplana-Meiera $(K M)$ i funkcji skumulowanej częstości występowania $(C I F)$ dla odpowiednio I i II rodzaju grup zdarzeń. Dla I rodzaju zdarzeniem kończącym jest wyrejestrowanie z dowolnego powodu, a dla II rodzaju - wyrejestrowanie z powodu podjęcia pracy. Wartości estymatora Kaplana-Meiera (rys. 1a) informują o prawdopodobieństwie pozostania w rejestrze urzędu po czasie $t$. Przykładowo po 6 miesiącach od momentu zarejestrowania było ono równe 0,4. Korzystając z estymatora CIF (wzór (9)), można wyznaczyć prawdopodobieństwo wyrejestrowania z urzędu (dowolna przyczyna) przed upływem czasu $t$. Przykładowo dla I rodzaju przed upływem 6 miesięcy było ono równe 0,6 . W przypadku II rodzaju (rys. 1b) prawdopodobieństwo podjęcia pracy przez bezrobotnego $\mathrm{w}$ ciągu pierwszych 6 miesięcy od zarejestrowania było równe 0,3 . Wynika z tego, że na prawdopodobieństwo wyrejestrowania z urzędu duży wpływ mogły mieć inne przyczyny niż podjęcie pracy.

Aby zbadać ten wpływ (ryzyko konkurujące), korzystając ze wzoru (7) wyznaczono funkcje $C I F_{k}(k=1,2, \ldots, 7)$ dla siedmiu przyczyn wyrejestrowania z urzędu pracy (zawartych w tab. 1). Na rys. 2a przedstawiono cztery wybrane estymatory $C I F_{k}$ dla III rodzaju: odmowa i praca jako osiągające wartości zdecydowanie większe niż pozostałe oraz dwie inne przyczyny związane z podjęciem pracy: praca (urząd) oraz podjęcie działalności gospodarczej. Prawdopodobieństwa zaistnienia pozostałych powodów wyrejestrowania: renta, zasiłek i emerytura, wyjazd za granicę oraz 


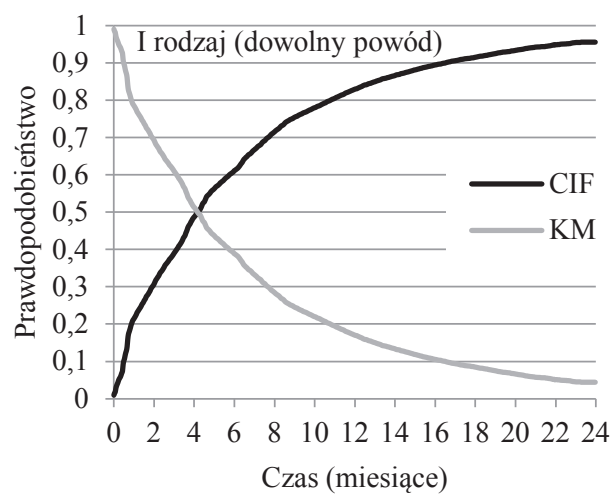

$\mathrm{b}$

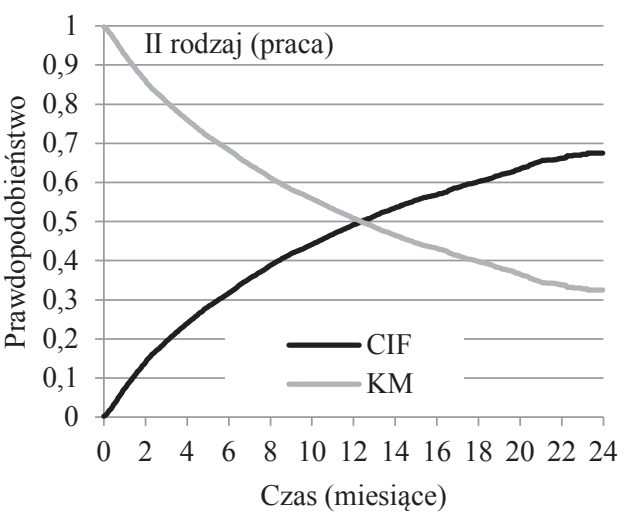

Rys. 1. Estymatory Kaplana-Meiera i CIF dla I i II rodzaju grup zdarzeń kończących proces obserwacji

Źródło: opracowanie własne.
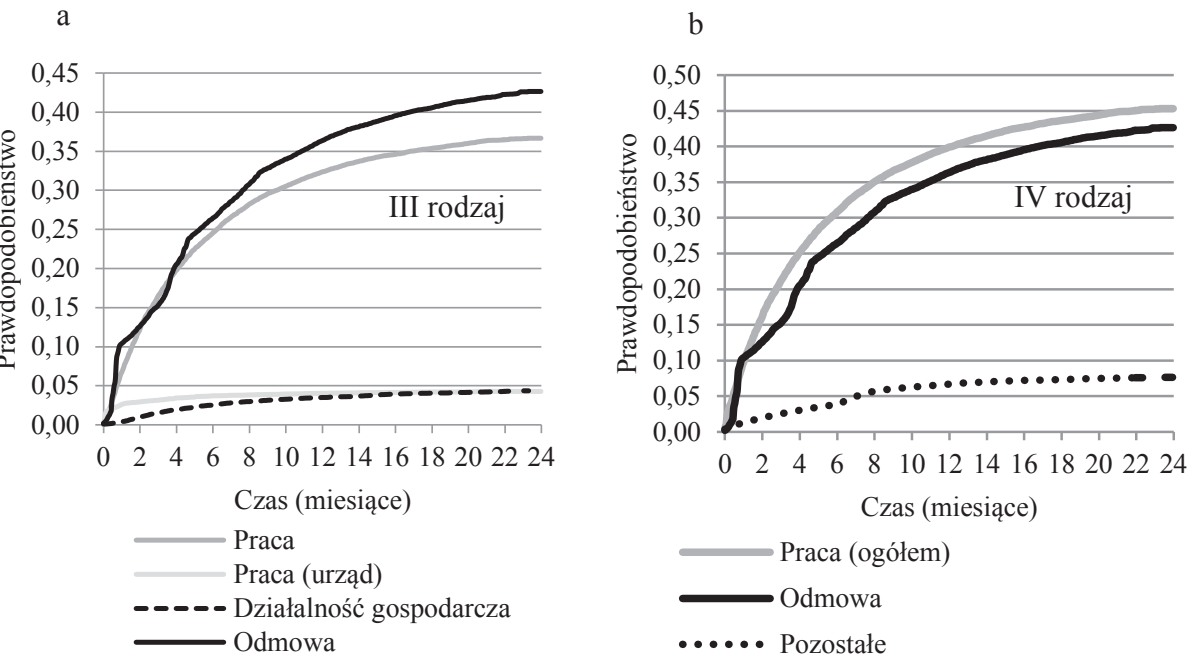

Rys. 2. Wartości estymatorów $C I F_{k}$ dla III i IV rodzaju grup zdarzeń kończących proces obserwacji Źródło: opracowanie własne.

pozostałe nie przekroczyły wartości 0,05 i miały wpływ marginalny na ryzyko całkowite. Analiza wartości tych funkcji wskazuje, że po 4 miesiącu od zarejestrowania prawdopodobieństwo wyrejestrowania bezrobotnego przez urząd z powodu ogólnie pojętej odmowy było większe od prawdopodobieństwa podjęcia pracy. Dla osoby bezrobotnej ważne jest podjęcie ogólnie pojętej pracy. Dlatego dalsza analiza polegała na wyznaczeniu funkcji $C I F_{k}(k=1,2,3)$ dla trzech powodów wyrejestrowań 
(IV rodzaj). Przy takiej klasyfikacji prawdopodobieństwo wyrejestrowań z powodu podjęcia jakiejkolwiek pracy było wyższe od prawdopodobieństwa odmowy, począwszy od drugiego miesiąca od momentu zarejestrowania. Pozostałe powody miały wpływ marginalny (rys. 2a).

Na rys. 3 przedstawiono konsekwencje przyjęcia II rodzaju zdarzeń kończących obserwację. Wartości tak wyznaczonego estymatora CIF (podjęcie pracy, II rodzaj) są dużo większe od wartości estymatora $C I F_{k}$ (podjęcie pracy, III rodzaj). Jak już wspomniano wcześniej, przyjęcie II rodzaju prowadzi do przeszacowania wartości ryzyka konkurującego. W przypadku przedstawionej analizy jest ono bardzo duże i w 24 miesiącu, kończącym obserwację, prawdopodobieństwo wyjścia do pracy dla II rodzaju zdarzeń $(0,68)$ jest większe aż o $84 \%$ od prawdopodobieństwa wyjścia do pracy dla III rodzaju zdarzeń $(0,37)$.

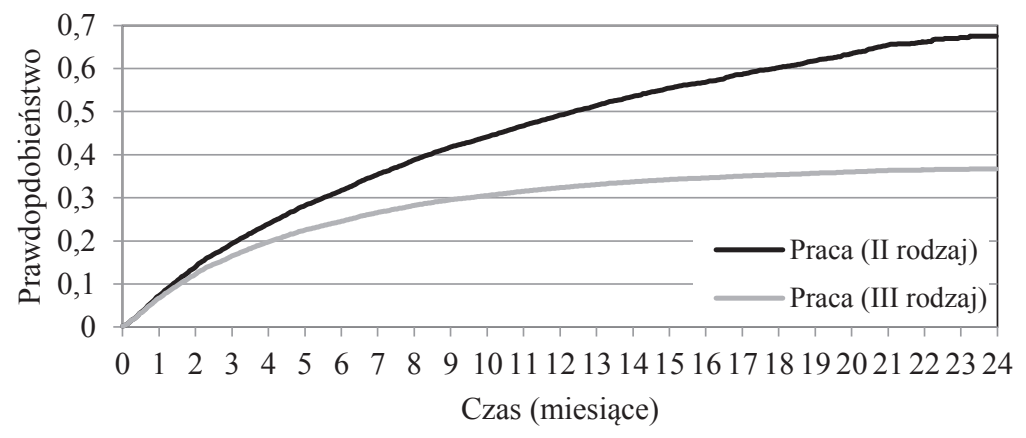

Rys. 3. Wartości estymatorów $C I F$ i $C I F_{k}$ dla zdarzenia praca (w ścisłym sensie) dla II i III rodzaju grup zdarzeń kończących proces obserwacji

Źródło: opracowanie własne.

Drugi etap badania polegał na ocenie ryzyk konkurujących z wykorzystaniem funkcji hazardu, czyli na oszacowaniu intensywności wychodzenia $\mathrm{z}$ bezrobocia. W przypadku braku zdarzeń konkurujących (I i II rodzaj) skorzystano z estymatora (12). W sytuacji wyróżnienia zdarzeń konkurujących (III i IV rodzaj) zastosowano estymator (11). Wartości obu estymatorów dla zdarzenia praca w przypadku II i III rodzaju grup zdarzeń są takie same, dlatego dalsza analiza dotyczyła zdarzeń I, III i IV rodzaju. Na rys. 4a przedstawiono wykres funkcji hazardu dla I i III rodzaju grup zdarzeń kończących obserwację, a na rysunku $4 \mathrm{~b}$ dla I i IV rodzaju. Intensywność wyrejestrowań z dowolnego powodu (I rodzaj) gwałtownie malała w 1 i 2 miesiącu oraz po 19 miesiącu od zarejestrowania. Jest ona zaznaczona czarną ciągła linią na obu rysunkach $4 \mathrm{a}$ i 4b. Na rys. 4a przedstawiono estymatory hazardu dla czterech zdarzeń kończących proces obserwacji: odmowa, praca, praca (urząd) i działalność gospodarcza (III rodzaj). Wartość estymatorów dla trzech pozostałych zdarzeń była 
a

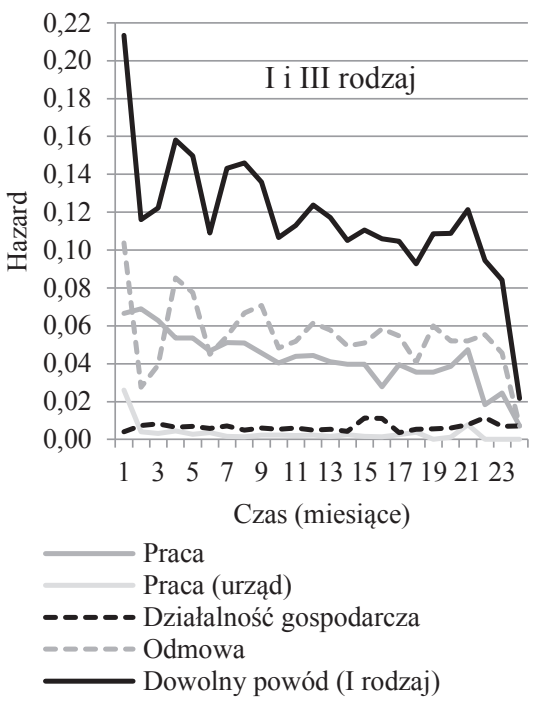

b

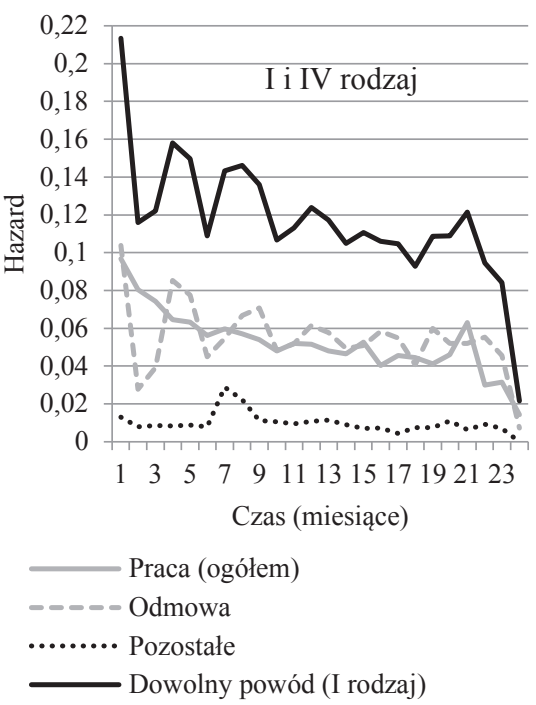

Rys. 4. Wartości funkcji hazardu dla I, III i IV rodzaju zdarzeń kończących proces obserwacji Źródło: opracowanie własne.

bliska 0 . Największy wpływ na wielkość intensywności wyrejestrowań z dowolnego powodu miały wyrejestrowania z powodu odmowy, szczególnie w pierwszym miesiącu od zarejestrowania. Na drugim miejscu była praca, a praca organizowana przez urząd oraz podjęcie działalności gospodarczej miały znaczenie raczej marginalne. $\mathrm{Na}$ rys. $4 \mathrm{~b}$ przedstawiono funkcje hazardu dla IV rodzaju zdarzeń. Intensywność wyrejestrowań z powodu podjęcia pracy (ogółem) jest nieco większa niż w przypadku III rodzaju, ale nadal nie przewyższa wartości hazardu dla przypadku odmowa. W przypadku pozostałych przyczyn zauważalny jest skok intensywności w 7 i 8 miesiącu. Wpływ na to miała dość duża wartość funkcji hazardu dla wyrejestrowań z powodu przyznania renty, zasiłku lub emerytury (odpowiednio: 0,023 i 0,016 ).

\section{Zakończenie}

Zastosowane w badaniu metody analizy trwania: funkcja skumulowanej częstości oraz model hazardu empirycznego, pozwoliły na ocenę wpływu innych niż praca przyczyn wyrejestrowania z urzędu pracy. Przeprowadzona analiza wskazała na to, że odmowa była bardzo silnym powodem wyrejestrowania osób bezrobotnych. Może to świadczyć o tym, że chęć podjęcia zatrudnienia nie była główną przyczyną zarejestrowania się bezrobotnego w urzędzie. Prawdopodobieństwo i intensywność wyrejestrowania z powodu odmowy były większe niż w przypadku podjęcia pracy 
w zawężonym sensie (III rodzaj). Subsydiowane formy pracy miały znaczenie marginalne, co wynika z ograniczonych środków, jakimi dysponuje urząd. Miały one jednak wpływ na zwiększenie prawdopodobieństwa i intensywności podjęcia pracy w sensie ogólnym (IV rodzaj).

\section{Literatura}

Aly E.A.A., Kochar S., McKeague E., 1994, Some tests for comparing cumulative incidence functions and cause-specific hazard rates, Journal of the American Statistical Association, vol. 89 (427), s. 994-999.

Bieszk-Stolorz B., Markowicz I., 2012, Wykorzystanie wielomianowego modelu logitowego do oceny szansy podjęcia pracy przez bezrobotnych, Prace Naukowe Uniwersytetu Ekonomicznego we Wrocławiu, nr 242, Taksonomia 19, s. 628-636.

Bryant J., Dignam J.J., 2004, Semiparametric models for cumulative incidence functions, Biometrics 60(1), s. 182-190.

Crowder M., 1994, Identifiability crises in competing risks, International Statistical Review, vol. 62, no. 3, s. 379-391.

Crowder M., 1996, On assessing independence of competing risks when failure times are discrete, Lifetime Data Analysis, 2(2), s. 195-209.

Crowder M., 1997, A test for independence of competing risks with discrete failure Times, Lifetime Data Analysis, vol. 3 (3), s. 215-223.

Gooley T.A., Leisenring W., Crowley J., Storer B.E., 1999, Estimation of failure probabilities in the presence of competing risks: new representations of old estimators, Statistics in Medicine, vol. 18 (6), s. 695-706.

Klein J.P., Moeschberger M.L., 2003, Survival Analysis: Techniques for Censored and Truncated Data. Second Edition, Springer-Verlag, New York.

Kleinbaum D., Klein M., 2005, Survival Analysis. A Self-Learning Text, Springer, New York.

Landmesser J.M., 2008a, Aktywność ekonomiczna ludności: klasyfikacja osób za pomoca wielomianowych modeli logitowych oraz jej związek z modelami hazardu dla czasów trwania, Prace Naukowe Uniwersytetu Ekonomicznego we Wrocławiu, nr 7 (1207), Taksonomia 15, s. 426-434.

Landmesser J.M., 2008b, Modele ryzyka konkurencyjnego dla czasu trwania czynności, Prace Naukowe Akademii Ekonomicznej w Katowicach, s. 371-385.

Marubini E., Valsecchi M., 1995, Analysing Survival Data from Clinical Trials and Observational Studies, John Wiley \& Sons, New York.

Pepe M.S., 1991, Inference for Events with Dependent Risks in Multiple Endpoint Studies, Journal of the American Statistical Association, vol. 86 (415), s. 770-778.

Sherif Bintu N., 2008, A Comparison of Kaplan-Meier and Cumulative Incidence Estimate in the Presence or Absence of Competing Risks in Breast Cancer Data, Master's Thesis, University of Pittsburgh. 